07.2

\title{
Модификация гребневых волноводов полупроводниковых лазеров фокусированным ионным пучком
}

\author{
(c) А.С. Паюсов ${ }^{1}$, М.И. Митрофранов ${ }^{1,2}$, Г.О. Корнышов ${ }^{3}$, А.А. Серин ${ }^{1}$, Г.В. Вознюк ${ }^{1}$, М.М. Кулагина ${ }^{1}$, \\ В.П. Евтихиев ${ }^{1}$, Н.Ю. Гордеев ${ }^{1}$, М.В. Максимов ${ }^{3}$, S. Breuer ${ }^{4}$ \\ 1 Физико-технический институт им. А.Ф. Иофффе РАН, Санкт-Петербург, Россия \\ ${ }^{2}$ Научно-технологический центр микроэлектроники и субмикронных гетероструктур РАН, Санкт-Петербург, Россия \\ ${ }^{3}$ Санкт-Петербургский национальный исследовательский Академический университет им. Ж.И. Алфёрова РАН, \\ Санкт-Петербург, Россия \\ ${ }^{4}$ Institute of Applied Physics, Technische Universität Darmstadt, Darmstadt, Germany \\ E-mail: plusov@mail.ioffe.ru
}

Поступило в Редакцию 28 июля 2021 г.

В окончательной редакции 12 сентября 2021 г.

Принято к публикации 28 сентября 2021 r.

\begin{abstract}
Проведено исследование травления гребневых волноводов торцевых полупроводниковых лазеров на двойной гетероструктуре с раздельным ограничением фокусированным ионным пучком. Показано, что по степени влияния на лазерные параметры существует три диапазона глубин травления: травление на небольшую глубину приводит лишь к модификации характеристик волновода, увеличение глубины травления вызывает уменьшение дифференциальной эффективности без изменения порогового тока, более глубокое травление вносит дефекты в активную область и вызывает одновременное ухудшение порогового тока и дифференциальной эффективности при существенной модификации оптических характеристик лазера.
\end{abstract}

Ключевые слова: фокусированный ионный пучок, полупроводниковый лазер, оптический волновод, одномодовый режим работы.

DOI: 10.21883/PJTF.2021.24.51801.18980

Гребневые волноводы торцевых полупроводниковых лазеров формируются в ходе постростовой обработки лазерных гетероструктур и определяют основные характеристики приборов, такие как качество выходного пучка, яркость излучения, максимальная мощность. Последняя возрастает с увеличением ширины волновода. Однако вместе с этим возникают условия для появления оптических мод высоких порядков, и становится возможной многомодовая лазерная генерация. Это в свою очередь приводит к снижению качества выходного пучка и яркости. Для получения максимальной мощности торцевых полупроводниковых лазеров, работающих в пространственно-одномодовом режиме, предлагались различные подходы: использование распределенных брэгговских отражателей и расширяющегося волновода [1], применение встроенных в волновод решеток (лазеры с распределенной обратной связью) [2], использование модифицированных зеркал [3], локальная модуляция эффективного показателя преломления [4]. Все они основаны на внедрении в конструкцию волновода или выходного зеркала элементов для пространственной и/или спектральной селекции оптических мод. Практическая реализация большинства предложенных подходов усложняет изготовление приборов, особенно на стадии создания тестовых образцов. При разработке новых конструкций полупроводниковых лазеров с использованием стандартных методов постростовой обработки приходится одновременно изготавливать несколько однотипных по конструкции приборов, различающихся по парамет- рам фильтрующих элементов в волноводе, а также референсные приборы. Это приводит к дополнительным временны́м и ресурсным затратам. При исследовании влияния конструкции прибора на характеристики излучения, особенно на этапе тестовых образцов, удобно использовать готовый прибор со стандартным волноводом и внести в него изменения. Для решения подобных задач хорошо подходит метод прямой литографии фокусированным ионным пучком (ФИП) (focused ion beam, FIB). Он позволяет без применения масок формировать литографический рисунок с нанометровым разрешением как в металлических, так и в полупроводниковых структурах. ФИП широко используется в полупроводниковой промышленности и в лабораториях исследовательских групп для подготовки образцов для просвечивающих электронных микроскопов и зондов для атомно-силовых микроскопов (АСМ), а также модификации интегральных схем, матричных приемников оптического излучения и пр. [5]. В последнее время ФИП начинают использоваться для создания нанорезонаторов в оптических волокнах [6] и модификации зеркал торцевых полупроводниковых лазеров [3]. Недостатком метода является образование радиационных дефектов (вакансии, междоузельные атомы и их комплексы) в полупроводниковой структуре под действием высокоэнергетических ионов. Радиационные дефекты создают глубокие уровни в запрещенной зоне полупроводника, что приводит к снижению внутреннего квантового выхода [7]. По данным работы [7] глубина формирования радиационных 
дефектов на порядок превышает теоретические оценки и при травлении гетероструктур $\mathrm{GaAs} / \mathrm{AlGaAs}$ ионами $\mathrm{Ga}^{+}$с энергией $30 \mathrm{keV}$ составляет $0.85 \mu \mathrm{m}$.

Первые эксперименты по травлению волноводов лазеров на двойной гетероструктуре (ДГС) показали, что даже при незначительной площади воздействия ФИП в $1 \mu \mathrm{m}^{2}$ возможно кардинальным образом поменять спектр лазерной генерации [8]. В структурах с раздельным ограничением (РО ДГС) носители локализованы в квантово-размерной активной области, что потенциально позволяет проводить травление большей площади и менять оптические свойства волновода и резонатора, не влияя при этом на рекомбинацию в активной области. Однако систематические данные по травлению гребневых волноводов РО ДГС-лазеров в литературе отсутствуют. В настоящей работе исследована зависимость основных излучательных характеристик диодных лазеров с узким гребневым волноводом от параметров их травления фокусированным ионным пучком (размера и глубины вытравленной области) с целью определения диапазонов травления, позволяющих независимо изменять оптические и электрические свойства.

Для экспериментов были выбраны лазеры с шириной волновода $W=4 \mu \mathrm{m}$. Лазерная гетероструктура была выращена методом газофазной эпитаксии из металлоорганических соединений. Активная область состоит из четырех слоев квантовых яма-точек $\mathrm{In}_{0.4} \mathrm{Ga}_{0.6} \mathrm{As}$ [9], разделенных слоями GaAs толщиной $40 \mathrm{~nm}$, и размещена в середине GaAs-волновода толщиной $450 \mathrm{~nm}$. Толщина p-эмиттера с контактным слоем составляет $1.15 \mu \mathrm{m}$, а $n$-эмиттера $-1.45 \mu \mathrm{m}$. Гребневые волноводы были сформированы методом плазмохимического травления. На поверхность гребня напылялся контактный металлический слой $\mathrm{Ag} / \mathrm{Mn} / \mathrm{Ni} / \mathrm{Au}$ шириной $2 \mu \mathrm{m}$ и толщиной $300 \mathrm{~nm}$, затем поверхность структуры вне гребневого волновода покрывалась слоем диэлектрика $\mathrm{Si}_{3} \mathrm{~N}$ толщиной $100 \mathrm{~nm}$, после чего на всю поверхность наносился сплошной металлический контакт $\mathrm{Cr} / \mathrm{Au}$ толщиной $200 \mathrm{~nm}$. Таким образом, из-за перекрытия различных слоев поверхность гребня не планарна и имеет рельеф (рис. 1,a). Исследуемые образцы с длиной резонатора $L=1.5 \mathrm{~mm}$ были смонтированы на медные теплоотводы с помощью индиевого припоя. Все характеристики были измерены при накачке импульсами тока длительностью $350 \mathrm{~ns}$ и частотой $3 \mathrm{kHz}$. До травления ФИП плотность порогового тока составляла $530-650 \mathrm{~A} / \mathrm{cm}^{2}$ при дифференциальной квантовой эффективности (ДКЭ) около 50\%. Длина волны лазерной генерации $1.09 \mu \mathrm{m}$ соответствует основному состоянию квантовых яма-точек. Исследования диаграмм направленности показали многомодовый характер лазерной генерации в латеральном направлении.

Травление гребневых волноводов проводилось в сверхвысоком вакууме фокусированным пучком ионов $\mathrm{Ga}^{+}$с энергией $30 \mathrm{keV}$ и рабочим током $500 \mathrm{pA}$. Ширина области травления, расположенной в $500 \mu \mathrm{m}$ от одного из лазерных зеркал, равнялась ширине волновода и
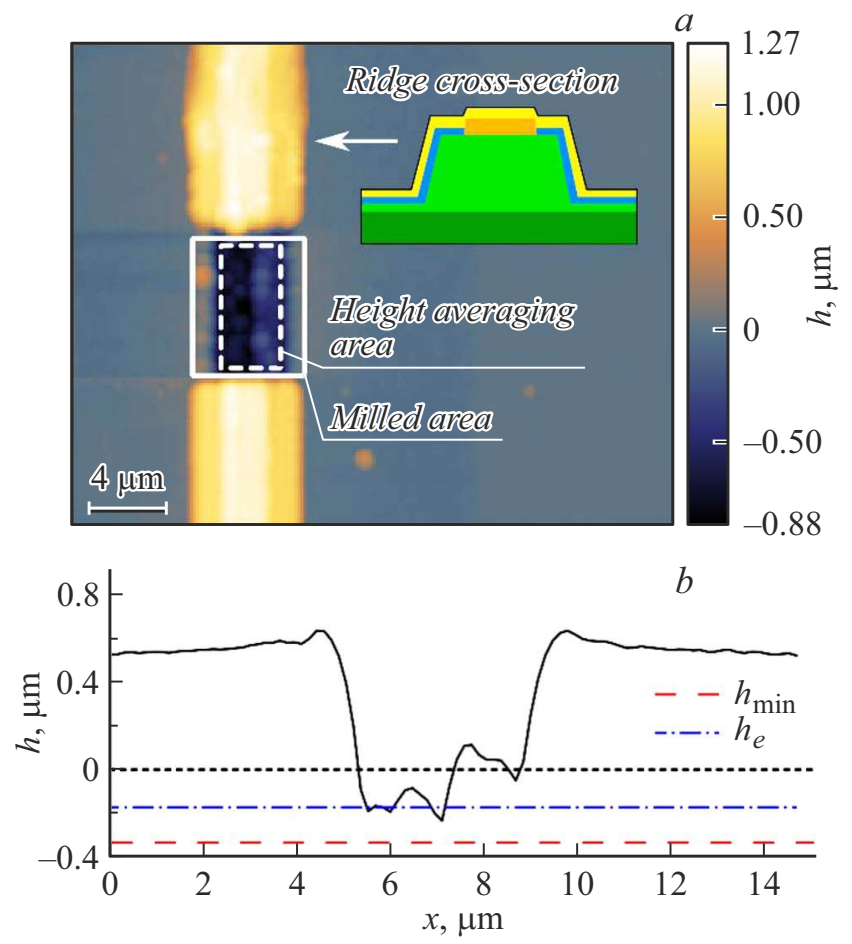

Рис. 1. $a-$ рельеф образца № 4, полученный с помощью АСМ. Высоты приведены относительно поверхности металлического контакта между полосками. Показаны область травления (сплошной прямоугольник) и область, в которой рассчитывалась средняя высота $h_{e}$ (штриховой прямоугольник). На вставке в правом верхнем углу приведен схематический профиль гребневого волновода. $b$ - профиль высоты поперек волновода в середине области травления. За начало отсчета принята граница волновод-p-обкладка.

составляла $4 \mu \mathrm{m}$, а длина $L_{f i b}$ для различных образцов составляла либо $10 \mu \mathrm{m}$, либо $50 \mu \mathrm{m}$. Такие относительно небольшие длины вытравленной области уже достаточны для влияния на оптические свойства волновода [4]. Фактическая глубина травления определялась по рельефам, полученным на АСМ в полуконтактном режиме работы. Все приводимые далее высоты были посчитаны относительно границы между волноводом и $p$-обкладкой (рис. $1, b)$. Ввиду того что поверхность контакта на вершине гребня была неоднородна по высоте, травление сфокусированным ионным пучком проводилось в два этапа. На первом этапе производилось выравнивание толщины металлического контакта на вершине гребня (планаризация), на втором - травление оставшегося металлического контакта и самого гребня. На рис. $1, b$ видна неоднородность рельефа на дне вытравленной области. Она обусловлена остаточной неоднородностью поверхности металлического контакта и влиянием наклонных стенок гребневого волновода на скорость и профиль травления. Поэтому мы определяли среднюю высоту $\left(h_{e}\right)$, а также минимальную высоту $\left(h_{\min }\right)$, как показано на рис. $1, a$. Существенный разброс между $h_{e}$ и $h_{\min }$ связан с наклоном боковых стенок волновода. 
Параметры травления и изменения основных характеристик приборов

\begin{tabular}{c|c|c|c|c|c|c}
\hline $\begin{array}{c}\text { Номер } \\
\text { образца }\end{array}$ & $L_{f i b}, \mu \mathrm{m}$ & Ионная доза, $10^{17} \mathrm{~cm}^{-2}$ & $h_{e}, \mu \mathrm{m}$ & $h_{\min }, \mu \mathrm{m}$ & $I_{t h \_f i b} / I_{t h}$ & $\eta_{D} / \eta_{D_{-} f i b}$ \\
\hline 1 & 10 & 1.68 & +1.4 & +0.84 & 1 & 1 \\
2 & 50 & 1.76 & +0.66 & +0.21 & 1 & 1.55 \\
3 & 50 & 1.76 & +0.71 & +0.08 & 1 & 1.42 \\
4 & 10 & 7.02 & -0.17 & -0.33 & 3.07 \\
5 & 10 & 7.02 & +0.08 & -0.43 & 1.53 & 2.55 \\
6 & 10 & 9.78 & -0.25 & -0.73 & 1.61 & 3.33
\end{tabular}

Пр имечан и е. $I_{t h \_f i b}$ и $\eta_{D \_f i b}-$ пороговый ток и дифференциальная эффективность после травления ФИП соответственно.

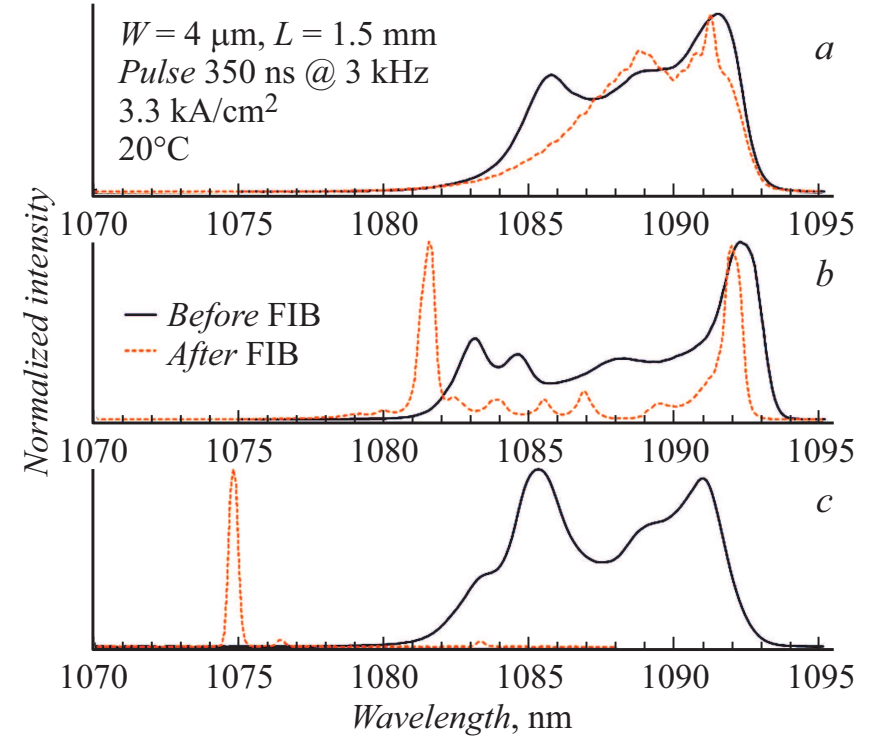

Рис. 2. Спектры лазерной генерации образцов № $1(a), 3$ (b) и $6(c)$ до и после травления ФИП.

При увеличении глубины травления параметры лазерных диодов ухудшаются (см. таблицу). По мере приближения фронта травления к активной области увеличивается вероятность формирования в ней радиационных дефектов, что приводит к снижению квантового выхода и соответственно к росту плотности порогового тока $I_{t h}$. Поэтому на плотность порогового тока больше влияет минимальная высота $h_{\min }$. Вместе с тем при небольшой глубине травления увеличение длины области в 5 раз не приводит к возрастанию порогового тока. Изменение дифференциальной эффективности $\eta_{D}$ обусловлено изменением параметров волновода. С увеличением длины области травления растут оптические потери, связанные с рассеянием в измененной части волновода. Таким образом, останавливая травление в p-обкладке за 200-300 nm до слоев активной области, можно вносить изменения в волновод без увеличения плотности порогового тока.

С увеличением глубины травления спектры лазерной генерации смещаются в коротковолновую область (рис. 2), что обусловлено ростом внутренних потерь.
Другим изменением оптических свойств волновода, наблюдаемым уже при минимальной глубине травления, является сужение спектров. Мы полагаем, что в этом случае протравленная секция работает аналогично пассивному модовому фильтру [10].

При дальнейшем увеличении глубины травления скачок эффективного показателя преломления вдоль волновода становится достаточным для того, чтобы лазерный резонатор разделился на два оптически связанных между собой резонатора. Эти системы хорошо изучены [11,12], и для них характерны одночастотная лазерная генерация, уменьшенный температурный сдвиг длины волны лазерной генерации, а также ее скачки, вызванные переключением с одной гибридной моды на другую. Температурные зависимости спектров лазерной генерации образцов № 5 и 6 имеют вид, типичный для лазеров с продольно-связанными резонаторами (рис. 3). Для этих лазеров температурный сдвиг длины волны определяется резонансом продольных мод двух связанных резонаторов и составляет $0.19 \mathrm{~nm} /{ }^{\circ} \mathrm{C}$. Для лазеров до травления температурная зависимость длины волны излучения определялась температурной зависимостью ширины запрещенной зоны, и температурный сдвиг со-

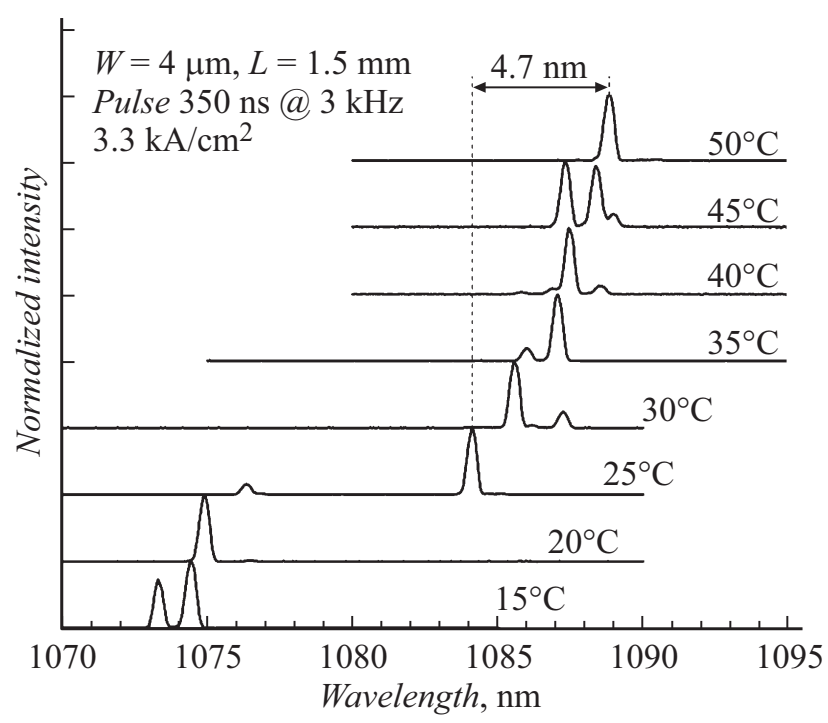

Рис. 3. Температурная зависимость спектров лазерной генерации образца № 6 после травления. 
ставлял $0.35 \mathrm{~nm} /{ }^{\circ} \mathrm{C}$. При переключении генерации с одной гибридной моды на другую длина волны изменяется на $9 \mathrm{~nm}$. Наличие нескольких линий в лазерном спектре связано с работой лазеров на нескольких латеральных модах. Это подтверждают измеренные диаграммы направленности.

Таким образом, мы провели систематическое исследование влияния травления методом ФИП гребневых волноводов торцевых полупроводниковых лазеров на их характеристики. Показано, что по степени влияния на лазерные параметры можно выделить три диапазона глубины травления. При остановке травления более чем за $400 \mathrm{~nm}$ до активной области плотность порогового тока и ДКЭ практически не изменяются и не зависят от площади травления при условии, что она относительно небольшая. При такой глубине травления свойства лазерного волновода и резонатора изменяются, а характер изменений зависит от размеров и расположения вытравленной области. Увеличение глубины травления до расстояний около $200 \mathrm{~nm}$ до активной области практически не меняет пороговый ток, но уменьшает ДКЭ. В этом диапазоне глубины травления резонатор лазера начинает разделяться на два оптически связанных резонатора. Увеличение порогового тока лазеров при травлении ФИП начинается при большой глубине, когда в активной области начинают формироваться радиационные дефекты. Результаты работы могут быть использованы как для создания мощных пространственно-одномодовых лазерных диодов, так и для улучшения качества пучка в латеральном направлении мощных лазеров с широким контактом [13].

\section{Финансирование работы}

Исследование выполнено при финансовой поддержке Министерства образования и науки РФ в рамках проекта № 0791-2020-0002, а также при поддержке Российского фонда фундаментальных исследований в рамках проектов № 19-32-90219 и 18-502-12081. S. Breuer благодарит за поддержку German Research Foundation (DFG) (project N 389193326).

\section{Конфликт интересов}

Авторы заявляют, что у них нет конфликта интересов.

\section{Список литературы}

[1] K. Paschke, F. Bugge, G. Blume, D. Feise, G. Erbert, Opt. Lett., 40, 100 (2015). DOI: 10.1364/OL.40.000100

[2] H. Wenzel, A. Klehr, M. Braun, F. Bugge, G. Erbert, J. Fricke, A. Knauer, P. Ressel, B. Sumpf, M. Weyers, G. Traenkle, Proc. SPIE, 5594, 110 (2004). DOI: 10.1117/12.569039
[3] Н.Ю. Гордеев, А.С. Паюсов, И.С. Мухин, А.А. Серин, М.М. Кулагина, Ю.А. Гусева, Ю.М. Шерняков, Ю.М. Задиранов, М.В. Максимов, ФТП, 53, 211 (2019). DOI: $10.21883 /$ FTP.2019.02.47100.8971 [N.Yu. Gordeev, A.S. Payusov, I.S. Mukhin, A.A. Serin, M.M. Kulagina, Yu.A. Guseva, Yu.M. Shernyakov, Yu.M. Zadiranov, M.V. Maximov, Semiconductors, 53, 200 (2019). DOI: $10.1134 / \mathrm{S} 1063782619020106]$.

[4] S. O’Brien, A. Amann, R. Fehse, S. Osborne, E.P. O'Reilly, J.M. Rondinelli, J. Opt. Soc. Am. B, 23, 1046 (2006). DOI: 10.1364/JOSAB.23.001046

[5] R.M. Langford, A.K. Petford-Long, M. Rommeswinkle, S. Egelkamp, Mater. Sci. Technol., 18, 743 (2002). DOI: $10.1179 / 026708302225003893$

[6] P. Romagnoli, M. Maeda, J.M. Ward, V.G. Truong, S.N. Chormaic, Appl. Phys. B, 126, 111 (2020). DOI: $10.1007 / \mathrm{s} 00340-020-07456-\mathrm{x}$

[7] G.V. Voznyuk, I.N. Grigorenko, M.I. Mitrofanov, D.N. Nikolaev, M.N. Mizerov, V.P. Evtikhiev, Semoconductors, 54, 1869 (2020). DOI: $10.1134 / \mathrm{S} 1063782620140316$

[8] C.R. Musil, B.D. Patterson, H. Auderset, Nucl. Instrum. Meth. Phys. Res. B, 127-128, 428 (1997). DOI: $10.1016 / \mathrm{S} 0168-583 \mathrm{X}(96) 00968-8$

[9] M.V. Maximov, A.M. Nadtochiy, S.A. Mintairov, N.A. Kalyuzhnyy, N.V. Kryzhanovskaya, E.I. Moiseev, N.Yu. Gordeev, Yu.M. Shernyakov, A.S. Payusov, F.I. Zubov, V.N. Nevedomskiy, S.S. Rouvimov, A.E. Zhukov, Appl. Sci., 10, 1038 (2020). DOI: 10.3390/app10031038

[10] Н.Ю. Гордеев, И.И. Новиков, А.М. Кузнецов, Ю.М. Шерняков, М.В. Максимов, А.Е. Жуков, А.В. Чунарева, А.С. Паюсов, Д.А. Лившиц, А.Р. Ковш, ФТП, 44, 1401 (2010). http://journals.ioffe.ru/articles/7253 [N.Yu. Gordeev, I.I. Novikov, A.M. Kuznetsov, Yu.M. Shernyakov, M.V. Maximov, A.E. Zhukov, A.V. Chunareva, A.S. Payusov, D.A. Livshits, A.R. Kovsh, Semiconductors, 44, 1357 (2010). DOI: $10.1134 / \mathrm{S} 1063782610100192]$.

[11] H. Temkin, J.P. van der Ziel, R.A. Linke, R.A. Logan, Appl. Phys. Lett., 43, 723 (1983). DOI: 10.1063/1.94490

[12] D. Marcuse, T.-P. Lee, IEEE J. Quantum Electron., 20, 166 (1984). DOI: 10.1109/JQE.1984.1072360

[13] J. Rong, E. Xing, L. Wang, S. Shu, S. Tian, C. Tong, L. Wang, Appl. Phys. Express, 9, 072104 (2016). DOI: $10.7567 /$ APEX.9.072104 